\title{
Molecular genetic evidence supporting the neoplastic nature of fibrous stroma in testicular teratoma
}

\author{
Liang Cheng ${ }^{1}$, Shaobo Zhang ${ }^{1}$, John N Eble ${ }^{1}$, Stephen DW Beck ${ }^{2}$, Richard S Foster ${ }^{2}$, \\ Mingsheng Wang ${ }^{1}$ and Thomas M Ulbright ${ }^{1}$ \\ ${ }^{1}$ Department of Pathology and Laboratory Medicine, Indiana University School of Medicine, \\ Indianapolis, IN, USA and ${ }^{2}$ Department of Urology, Indiana University School of Medicine, \\ Indianapolis, IN, USA
}

\begin{abstract}
Testicular teratoma typically consists of heterogeneous mixtures of diverse epithelial and stromal components. The biological nature and genetic characteristics of the fibrous stroma of testicular teratomas have not been thoroughly investigated. Chromosome 12p abnormalities are the hallmark genetic alterations of germ cell tumors. We studied chromosome 12p abnormalities in the fibrous stroma and other components of pure testicular teratomas from 32 patients using interphase fluorescence in situ hybridization. Overall, $72 \%(23 / 32)$ of pure testicular teratomas had chromosome 12p abnormalities. Isochromosome 12p or 12p overrepresentation independent of isochromosome 12p was detected in the fibrous stroma in $53 \%(17 / 32)$ and $41 \%(13 / 32)$ of cases, respectively. Among the 17 cases positive for isochromosome 12p, $8(47 \%)$ also had 12p overrepresentation. In $31 \%(10 / 32)$ cases, the fibrous stroma showed neither 12p overrepresentation nor isochromosome 12p. Isochromosome 12p and $12 p$ overrepresentation were identified, respectively, in the gastrointestinal-type epithelium of $14 / 23(61 \%)$ and $15 / 23(65 \%)$ cases; in the respiratory-type epithelium of $41 \%(7 / 17)$ and $41 \%(7 / 17)$ cases; in the squamous epithelium of $62 \%(8 / 13)$ and $54 \%(7 / 13)$ cases; and in the cartilage of $63 \%(5 / 8)$ and $38 \%$ (3/8) cases. Concordant chromosomal 12p abnormalities were observed between the fibrous stroma and epithelial elements of testicular teratomas. Our results indicate that the fibrous stroma of testicular teratomas frequently has genetic abnormalities similar to those of the epithelial components. Concordant chromosome 12p alterations between the fibrous stroma and epithelial elements provide further evidence that both epithelial and fibrous components of teratoma are derived from a common progenitor.
\end{abstract}

Modern Pathology (2012) 25, 1432-1438; doi:10.1038/modpathol.2012.99; published online 8 June 2012

Keywords: epithelial-mesenchymal transition; fluorescence in situ hybridization; germ cell tumors; isochromosome 12p; molecular genetics; teratoma stroma; testicular neoplasm

Teratomas are histologically diverse neoplasms that usually contain tissues from at least two or, more often, three germ layers (ectoderm, endoderm, and mesoderm). Testicular teratomas are present in both prepubertal and postpubertal males, but the prognosis and behavior differ greatly between these two groups. ${ }^{1}$ In children, teratomas most often occur before the age of 4 years, are generally pure (not associated with other germ cell tumor elements),

Correspondence: Professor L Cheng, MD, Department of Pathology and Laboratory Medicine, Indiana University School of Medicine, 350 West 11th Street, Room 4010, Indianapolis, IN 46202, USA. E-mail: lcheng@iupui.edu

Received 13 February 2012; revised 16 March 2012; accepted 22 March 2012; published online 8 June 2012 and behave in a benign fashion. In postpubertal patients, teratomas are uncommon as pure tumors, making up $<5 \%$ of germ cell tumors. However, teratoma is quite common as one component of a mixed germ cell tumor. Pure testicular teratomas in adults are regarded as malignant. They are thought to derive from the same malignant germ cells that give rise to other germ cell tumor components, possibly by transformation of such components..$^{2-4}$ Primary testicular teratomas may be associated with metastases of either teratomatous or other germ cell tumor types.

Abnormalities of chromosome 12p occur early in the evolution of testicular germ cell tumors, and there is evidence that $12 p$ overrepresentation is required for invasive behavior. ${ }^{5-8}$ Even in isochromosome $12 p$ 
(i(12p))-negative germ cell tumors, an overrepresentation of $12 p$ sequences can be demonstrated by interphase fluorescence in situ hybridization (FISH) ${ }^{5,9-16}$ Thus, chromosome $12 \mathrm{p}$ alterations are clinically relevant markers for tumors of germ cell origin. Multiple molecular and genetic studies show that testicular teratomas share the same chromosome $12 p$ abnormalities that are observed in all histological subtypes of the vast majority of testicular germ cell tumors. ${ }^{5}$ However, the genetic makeup of the stromal cells of teratomas has not been investigated sufficiently to determine whether these are reactive or integral to the neoplasm. In this study, we investigated chromosome $12 p$ abnormalities, either i(12p) or $12 p$ overrepresentation, in the fibrous stroma and other histological components in 32 pure testicular teratomas using interphase FISH.

\section{Materials and methods}

Thirty-two cases of postpubertal pure testicular teratoma were retrieved from the surgical pathology files of Indiana University Health hospitals. FISH testing was performed as previously described. ${ }^{10-17}$ Sections $4-\mu$ m-thick were prepared from buffered formalin-fixed, paraffin-embedded tissue blocks. The slides were deparaffinized with two 15-minute washes of xylene, and were subsequently washed twice with absolute ethanol, $10 \mathrm{~min}$ each. The slides were then air-dried in a fume hood. Next, the slides were treated in $0.1 \mathrm{mM}$ citric acid $(\mathrm{pH}$ 6.0; Zymed, Carlsbad, CA) at $95^{\circ} \mathrm{C}$ for $10 \mathrm{~min}$, rinsed in distilled water for $3 \mathrm{~min}$, and washed with $2 \times \mathrm{SSC}$ (standard saline citrate) for $5 \mathrm{~min}$. Digestion of the tissue was performed by applying $0.4 \mathrm{ml}$ of pepsin $(5 \mathrm{mg} / \mathrm{ml}$ in $0.01 \mathrm{~N} \mathrm{HCl}$ in $0.9 \% \mathrm{NaCl}$ ) (Sigma, St Louis, MO) at $37^{\circ} \mathrm{C}$ for $40 \mathrm{~min}$. The slides were rinsed with distilled water for $3 \mathrm{~min}$, washed again with $2 \times$ SSC for $5 \mathrm{~min}$, and air-dried.

Dual color FISH was performed by using a mixture of Spectrum Orange labeled centromeric $\alpha$ satellite DNA probe (CEP12) and Green labeled RP11-267D19 5-Fluorescein (12p11.21) DNA probes for chromosome 12p. CEP12 probe was from Vysis (Vysis, Downers Grove, IL) and chromosome 12p probe was from Empire Genomic (Empire Genomic, Buffalo, NY). The probes were diluted with $t$ DenHyb2 (Insitus, Albuquerque, NM) in a ratio of 1:50. In all, $5 \mu$ l of diluted probes were added to the slide in reduced light; the slides were covered with a $22 \times 22 \mathrm{~mm}$ coverslip and sealed with rubber cement. Denaturation was achieved by incubating the slides at $75^{\circ} \mathrm{C}$ for $10 \mathrm{~min}$ in a humidified box, and then the slides were hybridized at $37^{\circ} \mathrm{C}$ overnight.

The coverslips were removed and the slides were washed extensively twice with $45^{\circ} \mathrm{C}$ prewarmed $0.1 \times \mathrm{SSC} / 1.5 \mathrm{M}$ urea, $20 \mathrm{~min}$ for each, followed by a wash with $2 \times \mathrm{SSC}$ for $20 \mathrm{~min}$ and with $2 \times \mathrm{SSC} /$ $0.1 \% \mathrm{NP} 40$ for $10 \mathrm{~min}$ at $45^{\circ} \mathrm{C}$. The slides were further washed with room temperature $2 \times$ SSC for
$5 \mathrm{~min}$. The slides were air-dried and counterstained with $10 \mu \mathrm{l}$ DAPI (Insitus, Albuquerque, NM). The slides were covered and sealed with nail polish. The slides were examined using a Zeiss Axioplan 2 microscope (Ziess, Göettingen, Germany) with the following filters: SP-100 DAPI, FITC MF-101 for Green (12p11) and Gold 31003 for Spectrum Orange (CEP12) from Chroma (Chroma, Brattleboro, VT, USA).

The images were acquired with a CCD camera and analyzed with MetaSystem Isis software (MetaSystem, Belmont, MA). Five sequential focus stacks with $0.3 \mathrm{um}$ intervals were acquired and then integrated into a single image in order to reduce thickness-related artifacts. From each tumor section, 100 nuclei were scored for signals from CEP12 (red) and 12p11 (green) under the fluorescence microscope with $\times 1000$ magnification, and the ratio between green and red signals was subsequently calculated. We analyzed the spatial distribution of the green and red signals to detect the specific patterns of signal aggregation consistent with i(12p), as previously reported. ${ }^{10-17}$ The quantitative criteria to determine $12 \mathrm{p}$ overrepresentation were described previously. ${ }^{10-17}$

Classical seminoma specimens with known positive $i(12 p)$ and $12 p$ overrepresentation was used as a positive control for FISH analyses. In addition, we analyzed six cases of skin punch biopsies from patients without a history of germ cell tumors. None showed $\mathrm{i}(12 \mathrm{p})$ or $12 \mathrm{p}$ overrepresentation. Correlation of patients' age and chromosome $12 \mathrm{p}$ alterations was tested by the Pearson correlation coefficient test.

\section{Results}

Thirty-two cases of pure adult testicular teratoma were investigated for $i(12 p)$ and $12 p$ overrepresentation. The ages of the patients ranged from 20-53 years (mean, 33 years) at the time of the diagnosis. The pathological stage was pT1 for all cases.

The fibrous stroma in 22 of $32(69 \%)$ teratomas showed chromosome 12p anomalies (Figures 1-3, Table 1). In all, 17 (53\%) showed positive i(12p) and $13(41 \%)$ showed $12 \mathrm{p}$ overrepresentation independent of i(12p); 10 (31\%) did not have any chromosome 12 alterations. The gastrointestinal epithelium of 18 of $23(78 \%)$ cases had chromosome 12 abnormalities; $14(61 \%)$ showed i(12p), while 15 $(65 \%)$ showed $12 p$ overrepresentation. The respiratory epithelium of 10 of $17(59 \%)$ cases had chromosome 12 anomalies; i(12p) was detected in $7(41 \%)$ cases and $12 p$ overrepresentation in 7 (41\%) cases. Squamous epithelium was present in 13 cases. Chromosomal anomalies were detected in squamous epithelium in 9 of $13(69 \%)$ cases; 8 $(62 \%)$ with $\mathrm{i}(12 \mathrm{p})$ and $7(54 \%)$ with $12 \mathrm{p}$ overrepresentation. Also, 5 of $8(63 \%)$ cases that contained cartilaginous tissue showed $\mathrm{i}(12 \mathrm{p})$ in the 

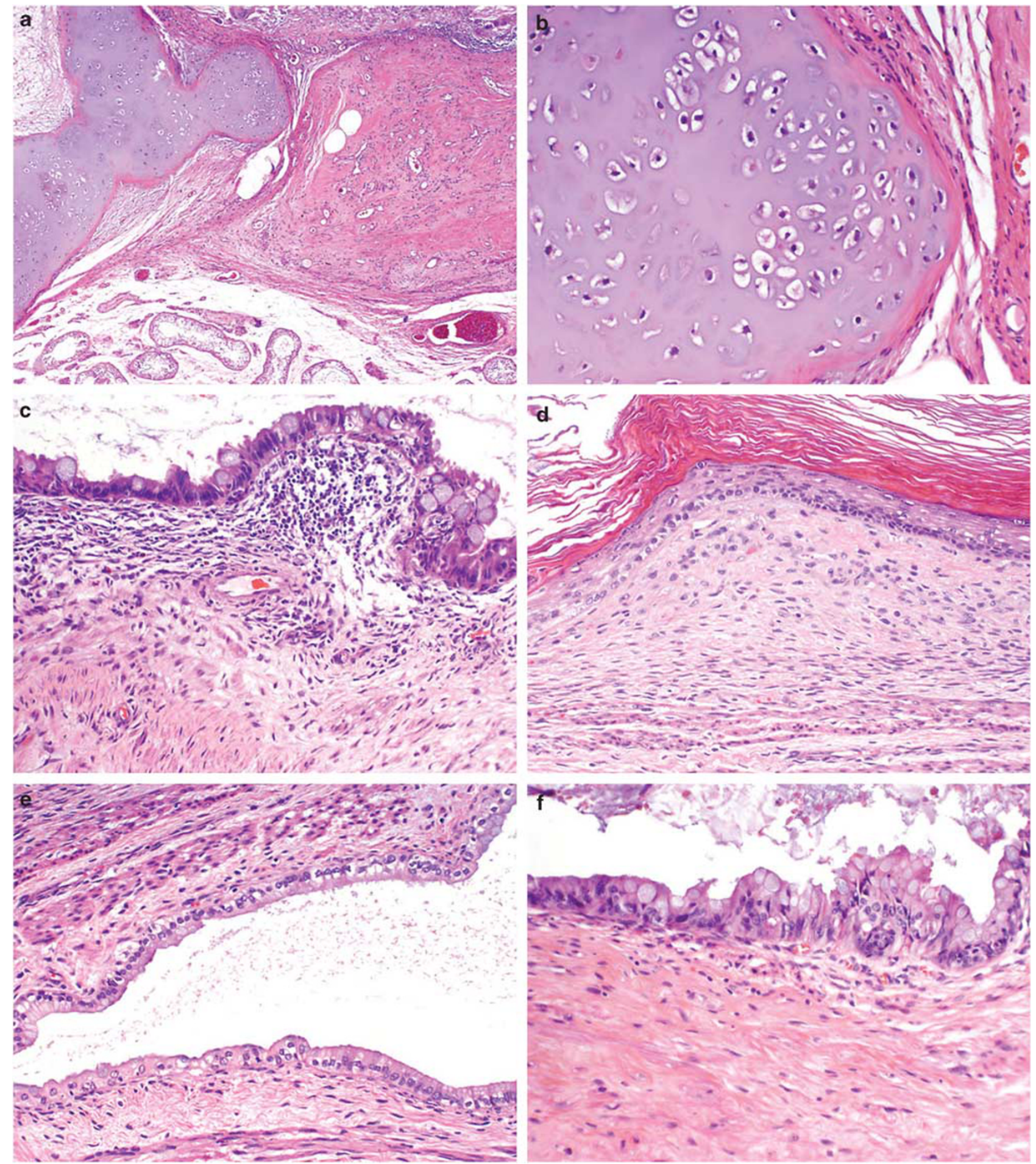

Figure 1 Different components of teratoma of the testis. (a-f) Testicular teratomas in adult patients are histologically diverse tumors that frequently contain tissues from three germ layers.

cartilage, while $3(38 \%)$ showed $12 p$ overrepresentation in the cartilage; 2 cases showed disomy in the cartilaginous component.

Overall, among 32 pure teratomas, chromosome $12 p$ abnormalities (i(12p), 12p overrepresentation, or both) were detected in $69 \%$ of fibrous stroma,
$78 \%$ of gastrointestinal epithelium, $59 \%$ of respiratory epithelium, $69 \%$ of squamous epithelium, and $75 \%$ of cartilaginous components; chromosome $12 p$ abnormalities were detectable in $72 \%$ of cases. No correlation was found between patient age and chromosome 12 alterations. 

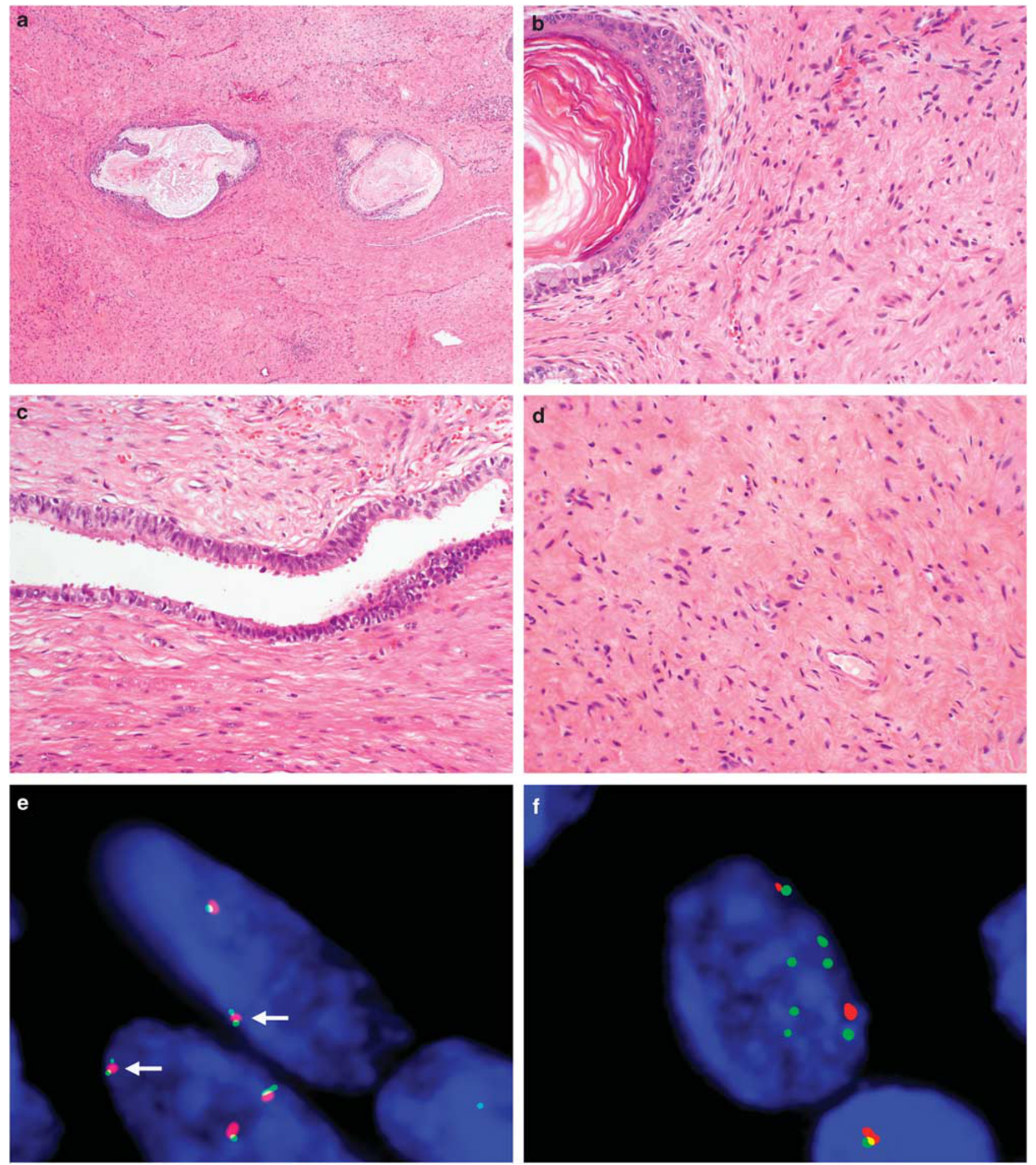

Figure 2 Morphological and genetic alterations of testicular teratoma. (a-d) Teratoma contains variable amounts of stromal tissue consisting of spindle cells. (e) Isochromosome $12 \mathrm{p}$ is present in the fibrous stroma as evidenced by two $12 \mathrm{p}$ signals (green) in close proximity to one centromeric signal (red; pointed by arrows). (f) FISH also shows chromosome 12p overrepresentation in stromal cells, characterized by two orange signals for the chromosome 12 centromere and numerous green signals for the 12p subtelomeric probe.

\section{Discussion}

Testicular teratomas in adult patients are histologically diverse tumors that frequently contain tissues from three germ layers. In this study, we investi- gated $\mathrm{i}(12 \mathrm{p})$ and chromosome $12 \mathrm{p}$ overrepresentation in the fibrous stroma and other histological components of 32 pure testicular teratomas using interphase FISH. Our results indicate that the fibrous stroma in testicular teratomas frequently 


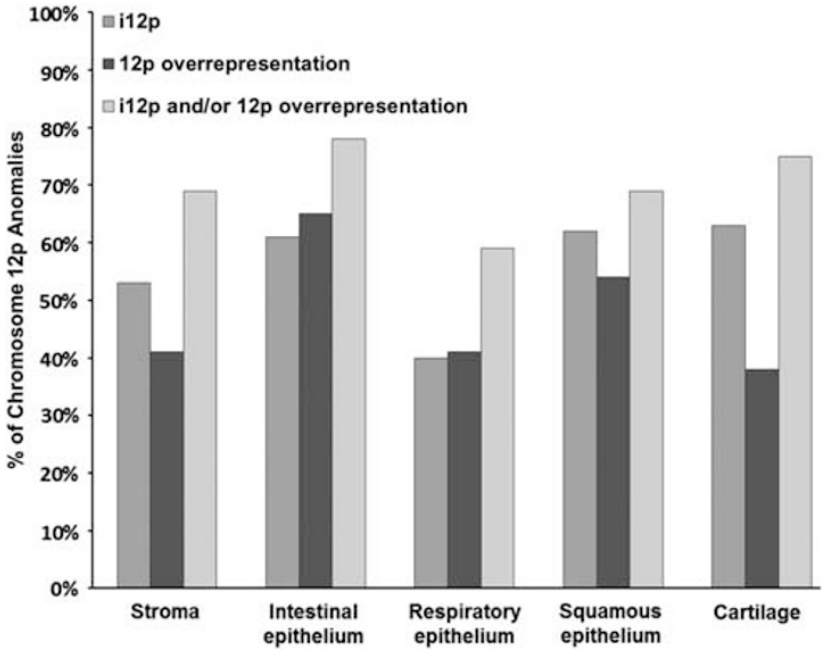

Figure 3 Chromosomal 12p anomalies in different components of 32 cases of pure testicular teratoma. Pattern-labeled bars represent the percentage of cases with detected $i(12 p), 12 p$ overrepresentation, or both. have characteristic genetic abnormalities similar to other teratomatous components, indicating that it is an integral neoplastic component of the tumor.

Most of the published studies on teratoma stromal cells have been performed on metastatic lesions and utilized loss of heterozygosity analysis and FISH to detect chromosome $12 \mathrm{p}$ alterations., ${ }^{3,18,19}$ In our previous study, we found that among the 25 patients with metastatic testicular teratoma, loss of heterozygosity was seen in $22(92 \%)$ of the teratoma specimens and in $16(64 \%)$ of the proximate stroma. ${ }^{19}$ Of these 16 cases, 8 had an identical pattern of allelic loss in the epithelial cells and in the proximate stroma at all 9 DNA loci studied. The remaining eight cases showed similar allelic loss in at least 1 of the 9 DNA loci analyzed. The results indicated that the stromal cells proximate to metastatic teratomas in postchemotherapy lymph node specimens have genetic abnormalities similar to those of the metastatic epithelial teratoma components. The concordant genetic alterations observed

Table 1 FISH analysis of isochromosome 12p and 12p overrepresentation in different components of teratoma of the testis

\begin{tabular}{|c|c|c|c|c|c|c|c|c|c|c|}
\hline \multirow[t]{3}{*}{ Case } & \multicolumn{10}{|c|}{ Testis teratoma components isochromosome $12 p$ and chromosome $12 p$ over-representation } \\
\hline & \multicolumn{2}{|c|}{ Stroma } & \multicolumn{2}{|c|}{$\begin{array}{c}\text { Gastrointestinal } \\
\text { epithelium }\end{array}$} & \multicolumn{2}{|c|}{$\begin{array}{l}\text { Respiratory } \\
\text { epithelium }\end{array}$} & \multicolumn{2}{|c|}{$\begin{array}{l}\text { Squamous } \\
\text { epithelium }\end{array}$} & \multicolumn{2}{|c|}{$\begin{array}{l}\text { Cartilaginous } \\
\text { tissue }\end{array}$} \\
\hline & $i(12 p)$ & $12 p O v$ & $i(12 p)$ & $12 p O v$ & $i(12 p)$ & $12 p O v$ & $i(12 p)$ & $12 p \mathrm{Ov}$ & $i(12 p)$ & $12 p O v$ \\
\hline 1 & - & - & + & + & & & & & & \\
\hline 2 & - & + & - & + & & & - & + & & \\
\hline 3 & + & + & + & - & - & + & + & - & & \\
\hline 4 & + & - & + & + & & & + & + & + & - \\
\hline 5 & + & + & & & & & & & + & - \\
\hline 6 & + & + & + & + & & & + & + & & \\
\hline 7 & - & - & - & - & & & & & - & - \\
\hline 8 & + & + & + & + & + & + & & & & \\
\hline 9 & - & + & + & + & & & & & & \\
\hline 10 & + & - & + & + & + & - & + & + & + & - \\
\hline 11 & - & - & - & - & - & - & & & & \\
\hline 12 & - & + & - & + & & & & & & \\
\hline 13 & + & - & + & + & & & & & & \\
\hline 14 & + & - & + & + & & & & & & \\
\hline 15 & + & - & + & + & & & & & & \\
\hline 16 & - & - & & & - & - & - & - & & \\
\hline 17 & - & - & & & - & - & & & & \\
\hline 18 & - & + & + & + & & & & & & \\
\hline 19 & + & - & + & - & & & + & - & - & - \\
\hline 20 & - & + & - & + & - & + & & & & \\
\hline 21 & + & + & & & + & - & & & & \\
\hline 22 & + & - & + & - & + & + & + & + & + & + \\
\hline 23 & + & + & & & + & + & + & + & + & + \\
\hline 24 & + & - & & & - & + & + & + & - & + \\
\hline 25 & + & + & + & + & + & + & & & & \\
\hline 26 & - & - & - & - & - & - & & & & \\
\hline 27 & - & - & - & - & - & - & - & - & & \\
\hline 28 & - & - & - & - & - & - & & & & \\
\hline 29 & - & - & & & - & - & & & & \\
\hline 30 & + & + & - & + & & & - & - & & \\
\hline 31 & + & - & & & + & - & & & & \\
\hline 32 & - & - & & & & & - & - & & \\
\hline$\%$ & 53 & 41 & 61 & 65 & 41 & 41 & 62 & 54 & 63 & 38 \\
\hline Sum \% & & & & & & & & & & \\
\hline
\end{tabular}

+, positive; -, negative; i(12p), isochromosome 12p; 12p Ov, chromosome 12p overrepresentation. 
in teratoma and stroma support that they both are derived from the same element of the original germ cell tumor or the same progenitor cell. The concept of teratomatous stroma was confirmed by another study from our group in which the chromosome 12p anomalies were found in 9 of 27 (33\%) retroperitoneal residual fibrous masses after chemotherapy. ${ }^{18}$ Our data support the concept that the fibrous stroma of testicular teratomas is one of the malignant teratoma components and that it, like the other teratoma components, has malignant potential.

Stroma may have a more active and important role in tumor biology than previously understood. ${ }^{20,21}$ Recent advances in cancer research have highlighted the critical role of the cancer-stroma interaction in the regulation of invasive processes. ${ }^{20,22-28}$ Tumor stroma provides growth factors, lytic enzymes, cytokines, angiogenesis modulators, and produces factors promoting tumor growth and the systemic effects of tumors. The concept of tumor stroma has been explored in various human cancers. ${ }^{20,22-29}$ It has been suggested that the stroma adjacent to breast carcinoma cells may have a role in inducing neoplastic transformation in adjacent epithelial cells. ${ }^{30-33}$

Our study, however, supports a more direct role of tumor stroma in the highly specialized situation of testicular teratoma than in other types of tumor; teratoma stroma itself is neoplastic. Subsequent genetic alterations of this fibrous component could lead to the clinical manifestation of a sarcoma secondarily arising from a more differentiated germ cell tumor element. It is well established that testicular teratoma patients occasionally develop secondary high-grade mesenchymal malignancies, presumably derived from the stroma. ${ }^{18,34-37}$ In a series by Motzer et $a l,{ }^{35} 63 \%$ of teratomas that developed a malignant component had a sarcoma. In the study of El Mesbahi et al, ${ }^{36}$ sarcoma was the most frequent tumor type among 14 teratoma patients with 'malignant transformation.' In the study of metastatic testicular teratomas reported by Brandli et $a{ }^{19}{ }^{19}$ the genetic changes of the teratoma and adjacent stroma were concordant, suggesting that the teratoma and stroma derived from the same original germ cell element or tumor progenitor cells. Similar observations were also made in other previous studies., ${ }^{438,39}$ Epithelial-mesenchymal transition may also be an important mechanism in the natural history of germ cell tumors and malignant transformation of teratoma. ${ }^{18,35,40-42}$ An earlier study suggests that exposure to platinum-based agents may induce cancer cells to exhibit a mesenchymal phenotype. ${ }^{43}$ It has also been suggested that malignant transformation of the stroma may be either through the transformation of differentiated elements or through progression of totipotential germ cells in the teratoma. ${ }^{1,18,35,44,45}$ All of these clinical and laboratory observations support that the stroma of testicular teratomas of men is not simply composed of coexisting accessory cells but that it is an integral neoplastic teratoma component.
In conclusion, our results indicate that the fibrous stroma of testicular teratomas frequently has the same genetic abnormalities as those of the usual teratomatous components. This provides evidence that the fibrous stroma is a malignant component of the tumor and that it is derived from the same common progenitor as the other teratoma components.

\section{Disclosure/conflict of interest}

The authors declare no conflict of interest.

\section{References}

1 Ulbright TM. Gonadal teratomas: a review and speculation. Adv Anat Pathol 2004;11:10-23.

2 Ulbright TM, Amin MB, Young RH. Tumors of the Testis, Adnexa, Spermatic Cord, and Scrotum Vol., Armed Forces Institute of Pathology: Washington DC, 1999.

3 Jones TD, Wang M, Sung MT, et al. Clonal origin of metastatic testicular teratomas. Clin Cancer Res 2006;12:5377-5383.

4 Kernek KM, Ulbright TM, Zhang S, et al. Identical allelic losses in mature teratoma and other histologic components of malignant mixed germ cell tumors of the testis. Am J Pathol 2003;163:2477-2484.

5 Oosterhuis JW, Looijenga LH. Testicular germ-cell tumours in a broader perspective. Nat Rev Cancer 2005;5:210-222.

6 Looijenga LH, de Munnik H, Oosterhuis JW. A molecular model for the development of germ cell cancer. Int J Cancer 1999;83:809-814.

7 Pienkowska-Grela B, Grygalewicz B, Bregula U. Overrepresentation of the short arm of chromosome 12 in seminoma and nonseminoma groups of testicular germ cell tumors. Cancer Genet Cytogenet 2002;134:102-108.

8 Samaniego F, Rodriguez E, Houldsworth J, et al. Cytogenetic and molecular analysis of human male germ cell tumors: chromosome 12 abnormalities and gene amplification. Genes Chromosomes Cancer 1990; 1:289-300.

9 Suijkerbuijk RF, Sinke RJ, Weghuis DE, et al. Amplification of chromosome subregion 12p11.2-p12.1 in a metastasis of an i(12p)-negative seminoma: relationship to tumor progression? Cancer Genet Cytogenet 1994;78:145-152.

10 Cossu-Rocca P, Zhang S, Roth LM, et al. Chromosome 12p abnormalities in dysgerminoma of the ovary: a FISH analysis. Mod Pathol 2006;19:611-615.

11 Kernek KM, Brunelli M, Ulbright TM, et al. Fluorescence in situ hybridization analysis of chromosome $12 \mathrm{p}$ in paraffin-embedded tissue is useful for establishing germ cell origin of metastatic tumors. Mod Pathol 2004;17:1309-1313.

12 Poulos C, Cheng L, Zhang S, et al. Analysis of ovarian teratomas for isochromosome 12p: evidence supporting a dual histogenetic pathway for teratomatous elements. Mod Pathol 2006;19:766-771.

13 Abbosh PH, Zhang S, Maclennan GT, et al. Germ cell origin of testicular carcinoid tumors. Clin Cancer Res 2008;14:1393-1396.

14 Sung MT, Maclennan GT, Lopez-Beltran A, et al. Primary mediastinal seminoma: a comprehensive 
assessment integrated with histology, immunohistochemistry, and fluorescence in situ hybridization for chromosome 12p abnormalities in 23 cases. Am J Surg Pathol 2008;32:146-155.

15 Cheng L, Zhang S, MacLennan GT, et al. Interphase fluorescence in situ hybridization analysis of chromosome $12 p$ abnormalities is useful for distinguishing epidermoid cysts of the testis from pure mature teratoma. Clin Cancer Res 2006;12:5668-5672.

16 Cheng L, Zhang S, Talerman A, et al. Morphologic, immunohistochemical, and fluorescence in situ hybridization study of ovarian embryonal carcinoma with comparison to solid variant of yolk sac tumor and immature teratoma. Hum Pathol 2010;41:716-723.

17 Emerson RE, Ulbright TM, Zhang S, et al. Nephroblastoma arising in a germ cell tumor of testicular origin. Am J Surg Pathol 2004;28:687-692.

18 Cheng L, Zhang S, Wang M, et al. Molecular genetic evidence supporting the neoplastic nature of stromal cells in 'fibrosis' after chemotherapy for testicular germ cell tumours. J Pathol 2007;213:65-71.

19 Brandli DW, Ulbright TM, Foster RS, et al. Stroma adjacent to metastatic mature teratoma after chemotherapy for testicular germ cell tumors is derived from the same progenitor cells as the teratoma. Cancer Res 2003;63:6063-6068.

20 Polyak K, Weinberg RA. Transitions between epithelial and mesenchymal states: acquisition of malignant and stem cell traits. Nat Rev Cancer 2009;9:265-273.

21 Diez-Torre A, Silvan U, De Wever O, et al. Germinal tumor invasion and the role of the testicular stroma. Int J Dev Biol 2004;48:545-557.

22 Taube JH, Herschkowitz JI, Komurov K, et al. Core epithelial-to-mesenchymal transition interactome gene-expression signature is associated with claudinlow and metaplastic breast cancer subtypes. Proc Natl Acad Sci U S A 2010;107:15449-15454.

23 Thiery JP, Acloque H, Huang RY, et al. Epithelialmesenchymal transitions in development and disease. Cell 2009;139:871-890.

24 Mani SA, Guo W, Liao MJ, et al. The epithelialmesenchymal transition generates cells with properties of stem cells. Cell 2008;133:704-715.

25 Cheng L, Zhang S, Alexander R, et al. Sarcomatoid carcinoma of the urinary bladder: the final common pathway of urothelial carcinoma dedifferentiation. Am J Surg Pathol 2011;35:e34-e46.

26 Sung MT, Wang M, MacLennan GT, et al. Histogenesis of sarcomatoid urothelial carcinoma of the urinary bladder: evidence for a common clonal origin with divergent differentiation. J Pathol 2007;211:420-430.

27 Tlsty TD, Coussens LM. Tumor stroma and regulation of cancer development. Annu Rev Pathol 2006;1:119-150.

28 De Wever O, Demetter P, Mareel M, et al. Stromal myofibroblasts are drivers of invasive cancer growth. Int J Cancer 2008;123:2229-2238.

29 Paterson RF, Ulbright TM, MacLennan GT, et al. Molecular genetic alterations in the laser-capturemicrodissected stroma adjacent to bladder carcinoma. Cancer 2003;98:1830-1836.
30 Fukino K, Shen L, Patocs A, et al. Genomic instability within tumor stroma and clinicopathological characteristics of sporadic primary invasive breast carcinoma. Jama 2007;297:2103-2111.

31 Kurose K, Hoshaw-Woodard S, Adeyinka A, et al. Genetic model of multi-step breast carcinogenesis involving the epithelium and stroma: clues to tumour-microenvironment interactions. Hum Mol Genet 2001;10:1907-1913

32 Moinfar F, Man YG, Arnould L, et al. Concurrent and independent genetic alterations in the stromal and epithelial cells of mammary carcinoma: implications for tumorigenesis. Cancer Res 2000;60: 2562-2566.

33 Patocs A, Zhang L, Xu Y, et al. Breast-cancer stromal cells with TP53 mutations and nodal metastases. N Engl J Med 2007;357:2543-2551.

34 Donadio AC, Motzer RJ, Bajorin DF, et al. Chemotherapy for teratoma with malignant transformation. J Clin Oncol 2003;21:4285-4291.

35 Motzer RJ, Amsterdam A, Prieto V, et al. Teratoma with malignant transformation: diverse malignant histologies arising in men with germ cell tumors. J Urol 1998;159:133-138.

36 El Mesbahi O, Terrier-Lacombe MJ, Rebischung C, et al. Chemotherapy in patients with teratoma with malignant transformation. Eur Urol 2007;51:1306-1312.

37 Spiess PE, Pisters LL, Liu P, et al. Malignant transformation of testicular teratoma: a chemoresistant phenotype. Urol Oncol 2008;26:595-599.

38 Rothe M, Albers P, Wernert N. Loss of heterozygosity, differentiation, and clonality in microdissected male germ cell tumours. J Pathol 1999;188:389-394.

39 van Echten J, Oosterhuis JW, Looijenga LH, et al. Mixed testicular germ cell tumors: monoclonal or polyclonal. Mod Pathol 1996;9:371-374.

40 Malagon HD, Valdez AM, Moran CA, et al. Germ cell tumors with sarcomatous components: a clinicopathologic and immunohistochemical study of 46 cases. Am J Surg Pathol 2007;31:1356-1362.

41 Devouassoux-Shisheboran M, Vortmeyer AO, Silver $\mathrm{SA}$, et al. Teratomatous genotype detected in malignancies of a non-germ cell phenotype. Lab Invest 2000; 80:81-86.

42 Eggener SE, Carver BS, Loeb S, et al. Pathologic findings and clinical outcome of patients undergoing retroperitoneal lymph node dissection after multiple chemotherapy regimens for metastatic testicular germ cell tumors. Cancer 2007;109:528-535.

43 Yang AD, Fan F, Camp ER, et al. Chronic oxaliplatin resistance induces epithelial-to-mesenchymal transition in colorectal cancer cell lines. Clin Cancer Res 2006;12:4147-4153.

44 Vortmeyer AO, Devouassoux-Shisheboran M, Li G, et al. Microdissection-based analysis of mature ovarian teratoma. Am J Pathol 1999;154:987-991.

45 Zhuang Z, Devouassoux-Shisheboran M, Lubensky IA, et al. Premeiotic origin of teratomas: is meiosis required for differentiation into mature tissues? Cell Cycle 2005;4:1683-1687. 